FERNANDES, A.A.; MARTINEZ, H.E.P.; PEREIRA, P.R.G.; FONSECA, M.C.M. Produtividade, acúmulo de nitrato e estado nutricional de cultivares de alface, em hidroponia, em função de fontes de nutrientes. Horticultura Brasileira, Brasília, v. 20, n. 2, p. 195-200, junho 2.002.

\title{
Produtividade, acúmulo de nitrato e estado nutricional de cultivares de alface, em hidroponia, em função de fontes de nutrientes
}

\author{
Adriano Alves Fernandes; Herminia Emilia Prieto Martinez; Paulo Roberto Gomes Pereira; Maira \\ Christina Marques Fonseca \\ UFV, Depto. Fitotecnia, 36.571-000, Viçosa-MG. E-mail: aalves@alunos.ufv.br
}

\section{RESUMO}

Foram avaliados a produtividade, acúmulo de nitrato e estado nutricional das cultivares de alface Regina, Babá de Verão e Grandes Lagos em cultivo hidropônico. O experimento foi conduzido no outono, de 25/03 a 20/05/99 em estufa da UFV. Foram avaliados dois conjuntos de fontes de nutrientes para compor as soluções nutritivas de crescimento vegetativo, que continham: 13,$6 ; 1,0 ; 7,0$; 4,48; e $2,5 \mathrm{mmol} \mathrm{L}^{-1}$ de N, P, K, Ca e Mg, respectivamente. O enxofre foi fornecido na concentração de 3,5 ou $2,5 \mathrm{mmol} \mathrm{L}^{-1}$ e os micronutrientes nas concentrações de 45;32; 46; $2 ; 0,9$; e $0,2 \mathrm{mmol}$ $\mathrm{L}^{-1}$ para $\mathrm{Fe}, \mathrm{Mn}, \mathrm{B}, \mathrm{Zn}, \mathrm{Cu}$ e Mo, respectivamente. A solução 1 forneceu $21,9 \%$ de N na forma amoniacal, e a solução 2, 100\% de N na forma de nitrato. As fontes de $\mathrm{P}$ empregadas foram fosfato monoamônico e fosfato monopotássico para as soluções 1 e 2 respectivamente, sendo que esta variação implicou no uso de diferentes quantidades de $\mathrm{KCl}$ nas soluções, o que proporcionou concentrações diferentes de $\mathrm{Cl}$, apresentando-se 6,76 e $2,18 \mathrm{mmol} \mathrm{L}^{-1}$ para as soluções 1 e 2, respectivamente. O cultivo foi feito em recipiente plástico com $8 \mathrm{~L}$ de capacidade, contendo três plantas. Os recipientes foram arranjados de modo que se obtivesse espaçamento de 0,22 $\mathrm{m}$ entre plantas. $\mathrm{O}$ delineamento experimental utilizado foi blocos ao acaso com seis repetições, em arranjo fatorial $2 \times 3$ (soluções $\mathrm{x}$ cultivares). Cada parcela foi constituída por três plantas. Foram avaliados o peso da matéria fresca da parte aérea, folhas, raízes e caule, número de folhas, comprimento do caule, porcentagem de matéria seca das folhas e estado nutricional da planta. A cv. Regina produziu $233 \mathrm{~g} \mathrm{planta}^{-1} \mathrm{e}$ a cv. Babá de Verão $193 \mathrm{~g} \mathrm{planta}^{-1}$. Os resultados obtidos para a cultivar Grandes Lagos não foram satisfatórios nas condições do experimento. A solução 1 proporcionou menores concentrações de nitrato para as cultivares Grandes Lagos (1082 mg kg ${ }^{1}$ de matéria fresca) e Regina (1092 $\mathrm{mg} \mathrm{kg}^{-1}$ de matéria fresca). As plantas apresentaram altas concentrações de $\mathrm{Mn}$, mas sem sintomas de toxidez. Em geral, a nutrição das plantas foi adequada para os dois conjuntos de fontes de nutrientes testados.

Palavras-chave: Lactuca sativa L., soluções nutritivas, nutrição mineral, cultivo sem solo.

\begin{abstract}
Nutrient sources affecting yield, nitrate concentration and nutritional status of lettuce cultivars, in hydroponics

The yield, nitrate concentration and nutritional status of the lettuce cvs. Regina, Babá de Verão and Great Lakes cultivated in hydroponic system were evaluated. The experiment was carried out in fall from March to June/99 in a greenhouse of the Universidade Federal de Viçosa, Brazil. Two groups of nutrient sources were evaluated to compose the nutritive solutions. The solutions were composed of $13.6 ; 1 ; 7 ; 4.48$; and $2.5 \mathrm{mmol} \mathrm{L}^{-1}$ of $\mathrm{N}, \mathrm{P}, \mathrm{K}, \mathrm{Ca}$ and $\mathrm{Mg}$, respectively. The sulfur contents were 3.5 or $2.5 \mathrm{mmol} \mathrm{L}^{-1}$ and micronutrient contents were $45 ; 32 ; 46 ; 2 ; 0.9$; and $0.2 \mathrm{mmol} \mathrm{L}^{-1}$ of $\mathrm{Fe}, \mathrm{Mn}, \mathrm{B}, \mathrm{Zn}, \mathrm{Cu}$ and $\mathrm{Mo}$, respectively. The solution 1 supplied $21,9 \%$ of $\mathrm{N}_{-} \mathrm{NH}_{4}^{+}$, and the solution $2,100 \%$ of $\mathrm{N}-\mathrm{NO}_{3}$. The phosphorus sources employed were $\mathrm{NH}_{4} \mathrm{H}_{2} \mathrm{PO}_{4}$ and $\mathrm{KH}_{2} \mathrm{PO}_{4}$ for the solutions 1 and 2, respectively, and this variation implied in the use of different amounts of $\mathrm{KCl}$ in the solutions, providing different concentrations of $\mathrm{Cl}$ of 6.76 and $2.18 \mathrm{mmol} \mathrm{L}^{-1}$ for the solutions 1 and 2, respectively. Lettuce plants were grown in plastic recipient with $8 \mathrm{~L}$ of capacity. The recipients containing three plants were arranged to obtain spacing of $0.22 \mathrm{~m}$ between plants. A randomized block design in a $2 \times 3$ (solutions x cultivars) factorial scheme, with six replications and three plants per plot was used. The fresh matter of shoots, leaves, roots and stems, number of leaves, stem length, leaves dry matter and plant nutricional status were evaluated. The yield of cv. Regina was $233 \mathrm{~g} \mathrm{plant}^{-1}$ and of cv. Babá de Verão was $193 \mathrm{~g} \mathrm{plant}^{-1}$. The cv. Great Lakes presented low yield. The solution 1 provided smaller nitrate concentrations for Great Lakes (1082 mg $\mathrm{kg}^{-1}$ in fresh matter) and Regina (1092 mg kg-1 in fresh matter). The plants presented high concentrations of $\mathrm{Mn}$, but without toxic symptoms. The plant nutritional status was satisfactory.
\end{abstract}

Keywords: Lactuca sativa L., nutritive solutions, mineral nutrition, soilless culture.

\section{(Aceito para publicação em 29 de janeiro de 2.002)}

\begin{abstract}
$\mathrm{A}$ alface é a hortaliça folhosa mais comercializada no Brasil, é boa fonte de vitaminas e sais minerais, destacando-se seu elevado teor de vitamina A. É adaptada a clima ameno, sendo própria para cultivo no inverno quando atinge as maiores produções. A limitação do cultivo no verão é a baixa qualidade do produto que eleva o preço nesse período (Delistoianov, 1997).
\end{abstract}

Para o cultivo hidropônico, têm sido encontradas boas alternativas comerciais, mesmo em mercados tradicionais, como as CEASAS. Com isso, enfatizou-se a qualidade associada à mercadoria. A alface cultivada em hidroponia, principal produto dessa linha, consegue preços superiores, mesmo quando comercializada na CEAGESP em engradados comuns. Seu preço fica entre 35 e $50 \%$ acima dos alcançados pelas cultivadas em sistemas tradicionais (Junqueira, 1999).

Em cultivo hidropônico sob ambiente protegido, a alface não corre os riscos dos fatores adversos do meio ambiente, fica protegida de geadas, chuvas intensas, granizo e ventos fortes, com ganho na produtividade e qualidade, fatores que contribuem para o fornecimen- 
to constante aos pontos de venda, trazendo satisfação ao consumidor.

O mercado atual prima pela qualidade dos seus produtos, com isso a produção hidropônica vem ganhando gradativamente o seu espaço. Nos grandes centros urbanos, torna-se cada vez mais comum a presença desses produtos nas prateleiras dos supermercados.

Pelo fácil manejo e curto ciclo de cultivo, a alface é a cultura chave para abrir caminho aos produtores que iniciam o cultivo hidropônico. Com 30-35 dias em solução nutritiva é possível obter plantas com características comerciais, trazendo rápido retorno financeiro. Contudo, é necessário acompanhamento técnico especializado, para que se tenha uma solução nutritiva balanceada que forneça nutrição adequada às plantas e evite, dentre outros problemas, o acúmulo excessivo de nitrato.

Este experimento teve como objetivo avaliar produtividade, acúmulo de nitrato e estado nutricional de cultivares de alface, em cultivo hidropônico, no período do outono.

\section{MATERIAL E MÉTODOS}

O experimento foi conduzido no outono, entre março e junho/99, em estufa da UFV, Viçosa (MG). Sementes de alface (Lactuca sativa L.) das cultivares Regina, Babá de Verão e Grandes Lagos foram semeadas em copos plásticos de $50 \mathrm{ml}$ contendo vermiculita. Da semeadura até o $7^{\circ}$ dia após a germinação, foram irrigadas com água pura; do $8^{\circ}$ ao $14^{\circ}$ dia irrigadas com solução de Steiner a $1 / 2$ força iônica; do $15^{\circ}$ ao $20^{\circ}$ dia irrigadas com solução de Steiner a 1 força iônica (Steiner, 1984). Todas as irrigações foram realizadas uma vez ao dia, após as 18 horas, em volume suficiente para saturar o substrato. No $12^{\circ}$ dia foi feito desbaste das plantas, deixando-se apenas uma planta/copo. Transcorridos 20 dias da emergência, as plantas foram selecionadas e transplantadas em número de três para cada recipiente plástico, de 8 litros de capacidade, contendo as soluções nutritivas (Tabela 1). Os recipientes foram arranjados de modo que se obtivesse espaçamento de 0,22 $\mathrm{m}$ entre plantas. As soluções nutritivas (solução 1 e 2) foram calculadas com base no proposto por diversos autores (Bloom-Zandstra \& Lampe, 1983; Ikeda \& Osawa, 1984; Os \& Kuiken, 1984; Prince \& Koontz, 1984; Steiner, 1984; Suzuki et al., 1984; Cramer \& Spurr, 1986).

O delineamento experimental foi blocos ao acaso com seis repetições, em arranjo fatorial $2 \times 3$. O primeiro fator teve como variáveis as soluções nutritivas, e o segundo, as cultivares Regina, Babá de Verão e Grandes Lagos. Cada parcela foi constituída por um recipiente plástico contendo três plantas.

A partir do transplantio, registraramse diariamente as temperaturas máximas e mínimas no interior da estufa. As soluções de crescimento vegetativo continham: 13,$6 ; 1,0 ; 7,0 ; 4,48$; e 2,5 mmol $\mathrm{L}^{-1}$ de $\mathrm{N}, \mathrm{P}, \mathrm{K}, \mathrm{Ca}$ e $\mathrm{Mg}$, respectivamente. $\mathrm{O}$ enxofre foi fornecido na concentração de 3,5 e $2,5 \mathrm{mmol} \mathrm{L}^{-1}$ para as soluções 1 e 2 , respectivamente; os micronutrientes nas concentrações de 45; 32; 46; 2; 0,9; e 0,2 $\mathrm{mmol} \mathrm{L}^{-1}$ para Fe, $\mathrm{Mn}, \mathrm{B}, \mathrm{Zn}, \mathrm{Cu}$ e Mo, respectivamente. A solução 1 forneceu $21,9 \%$ de $\mathrm{N}$ na forma amoniacal, e a solução 2, 100\% de N na forma de nitrato. As fontes de $\mathrm{P}$ empregadas foram fosfato monoamônico e fosfato monopotássico para as soluções 1 e 2, respectivamente. A variação na fonte de P implicou no uso de diferentes quantidades de $\mathrm{KCl}$ nas soluções, o que proporcionou concentrações de $\mathrm{Cl}^{-}$de 6,76 e $2,18 \mathrm{mmol} \mathrm{L}^{-1}$ para as soluções 1 e 2, respectivamente.

Para sustentar as plantas, utilizaramse tampas confeccionadas de placas de isopor revestidas com papel alumínio. Cada tampa tinha três orifícios para o encaixe de espumas, as quais serviram de suporte e proteção para as plantas. A oxigenação das soluções nutritivas foi feita por compressor de ar.

$\mathrm{O} \mathrm{pH}$ da solução foi monitorado e ajustado à faixa de 5,5 a 6,5 utilizandose $\mathrm{HCl}$ ou $\mathrm{NaOH}$. Para reposição dos nutrientes, com base na redução da condutividade elétrica, admitiu-se até $30 \%$ de depleção. Durante o experimento, a evapotranspiração de cada vaso foi monitorada e medida com uma proveta volumétrica. As reposições foram realizadas com água desionizada admitindo-se uma redução máxima em torno de $40 \%$ do volume do vaso.
Com a obtenção de plantas comerciais, 34 dias após o transplante (DAT), foram avaliados o peso da matéria fresca da parte aérea (MFP), peso da matéria fresca das folhas (MFF), peso da matéria fresca das raízes (MFR), número de folhas (NF), comprimento do caule (CCA), peso da matéria fresca do caule (MFC) e porcentagem de matéria seca das folhas (MSF), trabalhando-se com valor da média das três plantas por parcela.

Para a análise química das plantas, foi retirada uma amostra de aproximadamente $150 \mathrm{~g}$ de matéria fresca representativa de cada parcela. $\mathrm{O}$ material foi lavado em água desionizada e seco em estufa com circulação forçada de ar a $70^{\circ} \mathrm{C}$, até peso constante. Em seguida, foi pesado para a obtenção da matéria seca, moído em moinho tipo Wiley, equipado com peneira de 20 mesh. O N-total foi determinado pelo método Kjeldahl, descrito por Bremner (1965) e o N-NO ${ }_{3}^{-}$, de acordo com Cataldo et al. (1975). Os demais elementos foram analisados após mineralização pela digestão nítricoperclórica. O B foi determinado colorimetricamente pelo método da Azometina H (Wolf, 1974), após a mineralização por via seca em mufla a $550^{\circ} \mathrm{C}$. O P foi dosado colorimetricamente pelo método de redução do fosfomolibdato pela vitamina C, de acordo com Braga \& Defelipo (1974); o K, por fotometria de emissão de chama; o $\mathrm{Ca}, \mathrm{Mg}, \mathrm{Fe}, \mathrm{Mn}, \mathrm{Zn}$ e $\mathrm{Cu}$, por espectrofotometria de absorção atômica; e o S determinado por turbidimetria do sulfato (Blanchar et al., 1965).

Os dados foram submetidos à análise da variância e os efeitos dos tratamentos foram comparados pelo teste de Tukey a 5\% de probabilidade.

\section{RESULTADOS E DISCUSSÃO}

As soluções nutritivas 1 e 2 forneceram inicialmente uma condutividade elétrica (CE) de 2,64 e $2,23 \mathrm{mS} \mathrm{cm}^{-1}$, respectivamente, sendo necessária apenas uma reposição de nutrientes realizada no dia 13/05/99. Em cultivos hidropônicos comerciais, utiliza-se a correlação entre CE e concentração para a readição de nutrientes. Nas faixas de concentrações usadas, normalmente para a maioria das culturas, a 
Tabela 1. Conjuntos de fontes de nutrientes para compor as soluções nutritivas de crescimento vegetativo destinadas ao cultivo hidropônico da alface. Viçosa, UFV, 1999.

\begin{tabular}{|c|c|c|}
\hline \multirow{2}{*}{ Fontes } & Solução 1 & Solução 2 \\
\hline & \multicolumn{2}{|c|}{ g 1000L-1 } \\
\hline $\mathrm{KH}_{2} \mathrm{PO}_{4}$ & - & 134,78 \\
\hline $\mathrm{NH}_{4} \mathrm{H}_{2} \mathrm{PO}_{4}$ & 133,00 & - \\
\hline$\left(\mathrm{NH}_{4}\right)_{2} \mathrm{SO}_{4}$ & 144,00 & - \\
\hline $\mathrm{MgSO}_{4}$ & 625,00 & 616,02 \\
\hline $\mathrm{Ca}\left(\mathrm{NO}_{3}\right)_{2}$ & 941,00 & 943,95 \\
\hline $\mathrm{KNO}_{3}$ & 100,00 & 431,15 \\
\hline $\mathrm{KCl}$ & 475,00 & 153,62 \\
\hline $\mathrm{FeCl}_{3}$ & 12,17 & 12,17 \\
\hline $\mathrm{Na}_{2-}$ EDTA & 16,75 & 16,75 \\
\hline $\mathrm{MnSO}_{4}$ & 7,06 & 7,06 \\
\hline $\mathrm{H}_{3} \mathrm{BO}_{3}$ & 2,92 & 2,92 \\
\hline $\mathrm{ZnSO}_{4}$ & 0,43 & 0,43 \\
\hline $\mathrm{Na}_{2} \mathrm{MoO}_{4}$ & 0,06 & 0,06 \\
\hline $\mathrm{CuCl}_{2}$ & 0,12 & 0,12 \\
\hline
\end{tabular}

condutividade elétrica varia entre 2 a 4 $\mathrm{mS} \mathrm{cm}{ }^{-1}$ (Martinez, 1999).

Em relação ao volume de água evapotranspirada, houve necessidade de reposição somente a partir da $3^{\circ}$ semana após o transplantio. O volume máximo consumido foi obtido pela cultivar Regina na solução 1 , que totalizou ao final do experimento, através da soma das médias de consumo semanais $(3,3 ; 3,8$ e $4,8 \mathrm{~L}$ para $3^{\circ} ; 4^{\circ}$ e $5^{\circ}$ semanas, respectivamente), 11,9 litros por planta. Não houve diferença estatística significativa no consumo entre as soluções 1 e 2 para as cultivares estudadas.

Para as cultivares Babá de Verão, Grandes Lagos e Regina, as características de crescimento avaliadas foram pouco influenciadas pelas soluções $1 \mathrm{e}$ 2 (Tabela 2), apesar da presença de amônio e das quantidades mais elevadas de $\mathrm{Cl}^{-}$na solução 1 .

A cultivar Regina alcançou maior produção que as demais, sendo esse comportamento semelhante ao observado por Delistoianov (1997) em argila expandida. Essa cultivar também apresentou o maior número de folhas (Tabela 2), confirmando o resultado verificado por outros autores (Rosa et al., 1996; Toniolli \& Barros, 1996; Delistoianov, 1997).

As produções (MFP), 34 DAT, das cultivares Babá de Verão (193 g planta ${ }^{-1}$ ), sentou menor número de folhas em relação à Babá de Verão e Regina, grupo lisa, em ambas as soluções (Tabela 2).

A temperatura é o fator ambiental que mais influi na formação de cabeça, pois está relacionada com o pendoamento, o qual ocorrendo precocemente, antes do ponto de colheita, faz com que as folhas se tornem amargas na grande maioria das cultivares (Wititaker \& Ryder, 1974, citados por Zatarin, 1985). Reghin \& Otto (1991) consideram a cultivar Grandes Lagos como inadequada para o plantio em épocas quentes. Portanto, os resultados obtidos (Tabela 2) estão de acordo com as características da cultivar, que não produz bem em condições de altas temperaturas (Yokoyama et al., 1991).

Quanto ao aspecto nutricional das plantas, observa-se para as cultivares estudadas, quando comparadas com a alface tipo Boston, que as concentrações médias de $\mathrm{P}, \mathrm{K}, \mathrm{Fe}, \mathrm{Mn}$ e B estão acima da faixa considerada ideal por Jones Junior et al. (1991). Já as concentrações médias de N, Mg, Zn e Cu estão de acordo com o indicado como adequado pelo autor. Somente o Ca se encontra abaixo dessa faixa (Tabelas 3 e 4). Para a cultivar Regina, os teores de N, K, Mg, Fe, Mn e Zn estão um pouco acima dos valores observados por Delistoianov (1997) e o P, Ca, S e Cu apresentaram valores semelhantes. Para a cultivar Babá de Verão foi verificado comportamento similar ao da Regina, sendo os teores de N, K, Mg, Mn e Zn superiores. O P, Ca, S e Cu apresentaram valores semelhantes, e somente para o $\mathrm{Fe}$ foi observado teor menor que aqueles observados por Delistoianov (1997).

As soluções nutritivas empregadas apresentaram concentrações dentro da faixa preconizada para alface por Martinez (1997) e Furlani et al. (1999), para a maioria dos nutrientes, porém com concentrações relativamente elevadas de K, B, Cu e Mn, o que justifica, em parte, os resultados obtidos para as concentrações foliares de nutrientes nas cultivares de alface em estudo.

Quanto ao acúmulo de nitrato nas plantas, a solução 1 proporcionou menor acúmulo nas cultivares Grandes Lagos (1082 $\mathrm{mg} \mathrm{kg}^{-1}$ de matéria fresca) e Regina (1092 $\mathrm{mg} \mathrm{kg}^{-1}$ de matéria fres- 
Tabela 2. Matéria fresca da parte aérea (MFP), matéria fresca das folhas (MFF), matéria fresca das raízes (MFR), número de folhas (NF), comprimento do caule (CCA), matéria fresca do caule (MFC), matéria seca das folhas (MSF), por planta de alface, produzida em hidroponia, em função das soluções nutritivas. Viçosa, UFV, 1999.

\begin{tabular}{lcccc}
\hline \multicolumn{1}{c}{ Característica } & Solução & Babá de Verão & Grandes Lagos & Regina \\
\hline MFP(g) & 1 & $192,78 \mathrm{Ba}$ & $195,56 \mathrm{Ba}$ & $233,33 \mathrm{Aa}$ \\
& 2 & $185,00 \mathrm{Ba}$ & $170,00 \mathrm{Ba}$ & $214,72 \mathrm{Aa}$ \\
$\operatorname{MFF}(\mathrm{g})$ & 1 & $153,06 \mathrm{Ba}$ & $167,50 \mathrm{Ba}$ & $201,11 \mathrm{Aa}$ \\
& 2 & $148,61 \mathrm{Ba}$ & $145,56 \mathrm{Bb}$ & $189,17 \mathrm{Aa}$ \\
$\operatorname{MFR}(\mathrm{g})$ & 1 & $21,39 \mathrm{Ba}$ & $20,83 \mathrm{Ba}$ & $29,44 \mathrm{Aa}$ \\
& 2 & $20,00 \mathrm{Ba}$ & $13,61 \mathrm{Cb}$ & $26,94 \mathrm{Aa}$ \\
$\mathrm{NF}$ & 1 & $29,72 \mathrm{Ba}$ & $13,72 \mathrm{Ca}$ & $39,44 \mathrm{Aa}$ \\
& 2 & $29,44 \mathrm{Ba}$ & $13,00 \mathrm{Ca}$ & $37,28 \mathrm{Aa}$ \\
$\operatorname{CCA}(\mathrm{cm})$ & 1 & $13,97 \mathrm{Aa}$ & $14,38 \mathrm{Aa}$ & $9,13 \mathrm{Ba}$ \\
& 2 & $12,13 \mathrm{Aa}$ & $12,92 \mathrm{Aa}$ & $7,14 \mathrm{Ba}$ \\
$\operatorname{MFC}(\mathrm{g})$ & 1 & $39,72 \mathrm{Aa}$ & $28,06 \mathrm{Ba}$ & $32,22 \mathrm{Ba}$ \\
& 2 & $36,39 \mathrm{Aa}$ & $24,44 \mathrm{Ba}$ & $25,56 \mathrm{Bb}$ \\
$\operatorname{MSF}(\%)$ & 1 & $4,34 \mathrm{Aa}$ & $3,94 \mathrm{Aa}$ & $4,18 \mathrm{Aa}$ \\
& 2 & $4,17 \mathrm{ABa}$ & $3,60 \mathrm{Ba}$ & $4,22 \mathrm{Aa}$ \\
\hline
\end{tabular}

Médias seguidas de pelo menos uma mesma letra maiúscula nas linhas e minúscula nas colunas, não diferem entre si, a 5\% de probabilidade, pelo teste de Tukey.

Tabela 3. Concentrações dos macronutrientes $\left(\right.$ dag $\left.\mathrm{kg}^{-1}\right)$ em folhas de alface das cultivares Babá de Verão, Grandes Lagos e Regina produzidas em hidroponia, em função das soluções nutritivas. Viçosa, UFV, 1999.

\begin{tabular}{lcccccc}
\hline & \multicolumn{2}{c}{ Babá de Verão } & \multicolumn{2}{c}{ Grandes Lagos } & \multicolumn{2}{c}{ Regina } \\
\hline & \multicolumn{2}{c}{ Solução } & \multicolumn{2}{c}{ Solução } & \multicolumn{2}{c}{ Solução } \\
\hline $\mathrm{N}-$ Total & $\mathbf{1}$ & $\mathbf{2}$ & $\mathbf{1}$ & $\mathbf{2}$ & $\mathbf{1}$ & $\mathbf{2}$ \\
$\mathrm{N}-\mathrm{NO}_{3}$ & $4,88 \mathrm{a}$ & $4,82 \mathrm{a}$ & $4,68 \mathrm{a}$ & $4,53 \mathrm{a}$ & $4,58 \mathrm{a}$ & $4,79 \mathrm{a}$ \\
$\mathrm{P}$ & $0,76 \mathrm{a}$ & $0,50 \mathrm{a}$ & $0,62 \mathrm{~b}$ & $0,96 \mathrm{a}$ & $0,59 \mathrm{~b}$ & $0,91 \mathrm{a}$ \\
$\mathrm{K}$ & $0,90 \mathrm{a}$ & $0,91 \mathrm{a}$ & $0,81 \mathrm{a}$ & $0,72 \mathrm{a}$ & $0,85 \mathrm{a}$ & $0,85 \mathrm{a}$ \\
$\mathrm{Ca}$ & $7,06 \mathrm{a}$ & $7,14 \mathrm{a}$ & $7,06 \mathrm{a}$ & $7,04 \mathrm{a}$ & $7,01 \mathrm{a}$ & $7,10 \mathrm{a}$ \\
$\mathrm{Mg}$ & $1,88 \mathrm{a}$ & $2,12 \mathrm{a}$ & $1,43 \mathrm{~b}$ & $1,94 \mathrm{a}$ & $1,74 \mathrm{a}$ & $1,78 \mathrm{a}$ \\
$\mathrm{S}$ & $0,63 \mathrm{a}$ & $0,66 \mathrm{a}$ & $0,63 \mathrm{a}$ & $0,60 \mathrm{a}$ & $0,65 \mathrm{a}$ & $0,63 \mathrm{a}$ \\
$\mathrm{M}$ & $0,29 \mathrm{a}$ & $0,24 \mathrm{~b}$ & $0,28 \mathrm{a}$ & $0,25 \mathrm{a}$ & $0,25 \mathrm{a}$ & $0,22 \mathrm{a}$ \\
\hline
\end{tabular}

Médias, em cada cultivar, seguidas de pelo menos uma mesma letra na linha não diferem entre si, a $5 \%$ de probabilidade, pelo teste de Tukey.

ca). Isso ocorreu, possivelmente, pela maior presença de ânion cloreto e pelo fornecimento de $\mathrm{N}$ na forma amoniacal $(21,9 \%)$ na solução 1 , em relação à solução 2. Conforme Marschner (1995), a competição entre os ânions $\mathrm{Cl}^{-}$e $\mathrm{NO}_{3}^{-}$ contribui para a diminuição da concentração de $\mathrm{NO}_{3}{ }^{-}$nas folhas. Sady et al. (1995) e Abd-Elmoniem et al. (1996) relataram que folhas de alface apresentam menor acúmulo de nitrato com o fornecimento de $\mathrm{N}$ na forma de $\mathrm{NH}_{4}^{+}$e $\mathrm{NO}_{3}^{-}$, quando comparadas àquelas de nutrição exclusiva com $\mathrm{N}$ $\mathrm{NO}_{3}{ }^{-}$.Com o aumento do fornecimen- to de $\mathrm{N}$ na forma de $\mathrm{NO}_{3}^{-}$, a capacidade de redução do nitrato nas raízes torna-se um fator limitante e há um aumento da proporção de N-total translocado para a parte aérea na forma de $\mathrm{NO}_{3}^{-}$(Marschner, 1995).

As concentrações de $\mathrm{NO}_{3}$ - observadas para as três cultivares chegaram no máximo a $1.700 \mathrm{mg} \mathrm{kg}^{-1}$ de matéria fresca. Esse valor foi obtido pela cultivar Regina na solução 2, semelhante aos valores obtidos por Delistoianov (1997), e aproximadamente $50 \%$ dos limites máximos de 3.000 a $4.000 \mathrm{mg} \mathrm{kg}^{-1}$ tolerados na Europa (Benoit \& Ceustermans, 1989).
Para as cultivares Regina e Grandes Lagos não foi verificada diferença entre as soluções para concentrações de $\mathrm{S}$ nos tecidos. No entanto, para a cultivar Babá de Verão, observou-se maior concentração de $\mathrm{S}$ nas folhas das plantas crescidas na solução 1 (Tabela 3), provavelmente pelo fato da solução 1 apresentar maior concentração inicial de $\mathrm{S}$ $\left(3,5 \mathrm{mmol} \mathrm{L}^{-1}\right)$ que a solução $2(2,5$ mmol L-1) (Tabela 1).

A presença de amônio na solução 1 parece ter reduzido a concentração de Mn na cultivar Grandes Lagos, levando a aumentos na absorção de $\mathrm{Fe}$ e $\mathrm{Cu}$ (Ta- 
Tabela 4. Concentrações dos micronutrientes $\left(\mathrm{mg}_{\mathrm{kg}}{ }^{-1}\right)$ em folhas de alface das cultivares Babá de Verão, Grandes Lagos e Regina, produzidas em hidroponia, em função das soluções nutritivas. Viçosa, UFV, 1999.

\begin{tabular}{|c|c|c|c|c|}
\hline Característica & Solução & Babá de Verão & Grandes Lagos & Regina \\
\hline \multirow[t]{2}{*}{ MFP(g) } & 1 & $192,78 \mathrm{Ba}$ & $195,56 \mathrm{Ba}$ & $233,33 \mathrm{Aa}$ \\
\hline & 2 & $185,00 \mathrm{Ba}$ & $170,00 \mathrm{Ba}$ & $214,72 \mathrm{Aa}$ \\
\hline \multirow[t]{2}{*}{$\operatorname{MFF}(g)$} & 1 & $153,06 \mathrm{Ba}$ & $167,50 \mathrm{Ba}$ & $201,11 \mathrm{Aa}$ \\
\hline & 2 & $148,61 \mathrm{Ba}$ & $145,56 \mathrm{Bb}$ & 189,17Aa \\
\hline \multirow[t]{2}{*}{ MFR(g) } & 1 & $21,39 \mathrm{Ba}$ & $20,83 \mathrm{Ba}$ & $29,44 \mathrm{Aa}$ \\
\hline & 2 & $20,00 \mathrm{Ba}$ & $13,61 \mathrm{Cb}$ & $26,94 \mathrm{Aa}$ \\
\hline \multirow[t]{2}{*}{ NF } & 1 & $29,72 \mathrm{Ba}$ & $13,72 \mathrm{Ca}$ & $39,44 \mathrm{Aa}$ \\
\hline & 2 & $29,44 \mathrm{Ba}$ & $13,00 \mathrm{Ca}$ & $37,28 \mathrm{Aa}$ \\
\hline \multirow[t]{2}{*}{$\mathrm{CCA}(\mathrm{cm})$} & 1 & $13,97 \mathrm{Aa}$ & $14,38 \mathrm{Aa}$ & $9,13 \mathrm{Ba}$ \\
\hline & 2 & $12,13 \mathrm{Aa}$ & $12,92 \mathrm{Aa}$ & $7,14 \mathrm{Ba}$ \\
\hline \multirow[t]{2}{*}{$\operatorname{MFC}(g)$} & 1 & $39,72 \mathrm{Aa}$ & $28,06 \mathrm{Ba}$ & $32,22 \mathrm{Ba}$ \\
\hline & 2 & $36,39 \mathrm{Aa}$ & $24,44 \mathrm{Ba}$ & $25,56 \mathrm{Bb}$ \\
\hline \multirow[t]{2}{*}{ MSF $(\%)$} & 1 & $4,34 \mathrm{Aa}$ & 3,94 Aa & $4,18 \mathrm{Aa}$ \\
\hline & 2 & $4,17 \mathrm{ABa}$ & $3,60 \mathrm{Ba}$ & $4,22 \mathrm{Aa}$ \\
\hline
\end{tabular}

Médias, em cada cultivar, seguidas de pelo menos uma mesma letra na linha não diferem entre si, a 5\% de probabilidade, pelo teste de Tukey.

bela 4). É possível que o fato possa, parcialmente, justificar-se pela competição entre cátions. A presença de $\mathrm{NH}_{4}^{+}$restringiu a absorção de $\mathrm{Mn}$, proporcionando maior absorção de $\mathrm{Fe}$ e $\mathrm{Cu}$ quando comparado a solução 2. Observou-se ainda, para essa mesma cultivar na solução 1 , aumento na absorção de $\mathrm{B}$, o que se justifica provavelmente ao menor $\mathrm{pH}$ promovido pela absorção do amônio.

Altas concentrações de Mn diminuem a absorção de Fe (Marschner, 1995), o que pode ser observado para a cultivar Grandes Lagos (Tabela 4). De acordo com Jones Junior et al. (1991), concentrações de $\mathrm{Mn}$ acima de $250 \mathrm{mg}$ $\mathrm{kg}^{-1}$ são consideradas altas. Segundo Marschner (1995), a toxidez por Mn causa necroses e manchas nas folhas. Em algumas plantas da variedade Regina apareceram pontuações que não se caracterizaram como distúrbio nutricional por não apresentarem gradiente entre folhas mais velhas e mais jovens e nem distribuição simétrica em todos os lados da planta. Também não foi possível caracterizá-las como doenças após tentativa de isolamento do agente causal. Apesar dos valores obtidos estarem bem elevados, não foram observados sintomas de intoxicação.

As cultivares Regina, Babá de Verão e Grandes Lagos apresentaram 233, 193 e 196 g planta $^{-1}$ de matéria fresca na parte aérea, respectivamente. A solução 1 proporcionou menores concentrações de nitrato para as cultivares Regina e Grandes Lagos. A concentração máxima de nitrato obtida (1.700 mg kg${ }^{1}$ de matéria fresca) não compromete $o$ consumo. A nutrição das plantas foi ade- quada para os dois conjuntos de fontes de nutrientes testados.

\section{AGRADECIMENTOS}

À UFV pela oportunidade de realização do trabalho e À CAPES pela concessão da bolsa de pesquisa ao primeiro autor.

\section{LITERATURA CITADA}

ABD-ELMONIEM, E.M.; ABOU-HADID, A.F.; EL-SHINAWY, M.Z.; EL-BELTAGY, A.S.; EISSA, A.M. Effect of nitrogen form on lettuce plant grown in hydroponic system. Acta Horticulturae, v. 434, p. 47-52, 1996.

BENOIT, F.; CEUSTERMANS, N. Recommendations for the commercial production of butterheard lettuce in NFT. Soilless Culture, $\mathrm{n}$. 5, p. 1-12, 1989.

BLANCHAR, R.W.; REHM, G.; CALDWELL, A.C. Sulfur in plant material by digestion with nitric and perchloric acid. Proceedings-Soil Science Society of America, v. 29, n. 1, p. 71-72, 1965.

BLOOM-ZANDSTRA, G.; LAMPE, E.M. The effect of cloride and sulfate salts on the nitrate content in lettuce plants (Lactuca sativa $\mathrm{L}$.). Journal of Plant Nutrition, v. 6, n. 7, p. 611-628, 1983.

BRAGA, J.M.; DEFELIPO, B. Determinação espectrofotométrica de fósforo em extratos de solos e plantas. Revista Ceres, Viçosa, v. 21, n. 113, p. 73-85, 1974.

BREMNER, J.M. Total nitrogen In: BLACK, C.A., ed. Methods of soil analysis. Madison: American Society of Agronomy, 1965. part 2, p. 1149-1178.

ATALDO, D.A.; HAROON, M.; SCHRADER, L.E.; YOUNGS, V.L. Rapid colorimetric determination of nitrate in plant tissue by nitrification of salicylic acid. Communications in Soil Science and Plant Analysis, v. 6, n. 1, p. 7180, 1975.

CRAMER, G.R.; SPURR, A.R. Responses of lettuce to salinity. I. Effects of $\mathrm{NaCl}$ and $\mathrm{Na}_{2} \mathrm{SO}_{4}$ on growth. Journal of Plant Nutrition, v. 9, n. 2, p. 115-130, 1986.
DELISTOIANOV, F. Produção, teores de nitrato e capacidade de rebrota de cultivares de alface, sob estufa, em hidroponia e solo, no verão e outono. Viçosa: UFV, 1997. 76 p. (Tese mestrado). FURLANI， P.R.; SILVEIRA， L.C.P.; BOLONHEZI, D.; FAQUIN, V. Cultivo hidropônico de plantas. Campinas: Instituto Agronômico, 1999. 52 p. (Boletim Técnico, n. 180). GUALBERTO, R.; RESENDE, F.V.; BRAZ, L.T. Competição de cultivares de alface sob cultivo hidropônico 'NFT' em três diferentes espaçamentos. Horticultura Brasileira, Brasília, v. 17 , n. 2, p. 155-158, 1999.

IKEDA, H.; OSAWA, T. Lettuce growth as influenced by $\mathrm{N}$ source and temperature of the nutrient solution. In: INTERNATIONAL CONGRESS ON SOILLESS CULTURE, 6 ., 1984, Lunteren. Proceedings...Lunteren: International Society of Soiless Culture, 1984. p. 273-284.

JONES JUNIOR, J.B.; WOLF, B.; MILLS, H.A. Plant analysis handbook, a practical sampling, preparation, analysis, and interpretation guide. Georgia, USA: Micro-Macro, 1991. 183 p.

JUNQUEIRA, A.H. Hortaliças, novos caminhos no ambiente protegido. AGRIANUAL 99 - Anuário da Agricultura Brasileira. São Paulo: FNP Consultoria \& Comércio, 1999. p. 35-38.

MARSCHNER, H. Mineral nutrition of higher plants. 2. ed. New York: Academic Press, 1995. $889 \mathrm{p}$.

MARTINEZ, H.E.P. Formulação de soluções nutritivas para cultivos hidropônicos comerciais. Jaboticabal: FUNEP, 1997. 31 p. (Boletim).

MARTINEZ, H.E.P. O uso do cultivo hidropônico de plantas em pesquisa. 2. ed. Viçosa: Imprensa Universitária, 1999. 47 p. (Cadernos Didáticos 1) OS, E.A.V.; KUIKEN, J.C.J. Mechanisation of lettuce growing in nutrient film technique. In: INTERNATIONAL CONGRESS ON SOILLESS CULTURE, 6., 1984, Lunteren. Proceedings...Lunteren: International Society of Soiless Culture, 1984. p. 483-492.

PRINCE, R.P.; KOONTZ, H.V. Lettuce production from a system approach. In: INTERNATIONAL CONGRESS ON SOILLESS CULTURE, 6., 1984, Lunteren. Proceedings....Lunteren: International Society of Soiless Culture, 1984. p. 533-545.

REGHIN, M.Y.; OTTO, R.F. Competição de cultivares de alface (Lactuca sativa L.) na época quente de Ponta Grossa, PR. Horticultura Brasileira, Brasília, v. 9, n. 1, p. 55, 1991. 
RIBEIRO, L.G.; RODRIGUES, C.; EDSON FILHO. F. Avaliação de cultivares de alface no plantio de primavera-verão em Alegre-ES Horticultura Brasileira, Brasília, v. 10, n. 1, p. 41, 1992.

ROSA, J.; PEIL, R.M.; MARTINS, S.R.; MENDES, M.E.; SCHWENGBER, J.E. Avaliação de cultivares de alface em estufa plástica no inverno no sul do Rio Grande do Sul. Horticultura Brasileira, Brasília, v. 14, n. 1, p. 113, 1996.

SADY, W.; ROZEK, S.; MYCZKOWSKI, J. Effect of different forms of nitrogen on the quality of lettuce yield. In: GROWING MEDIA E PLANT NUTRITION. Acta Horticulturae, v. 401, p. 409-416, 1995.
STEINER, A.A. The universal nutrient solution. In: INTERNATIONAL CONGRESS ON SOILLESS CULTURE, 6., 1984, Lunteren. Proceedings... Lunteren: International Society of Soiless Culture, 1984. p. 633-649.

SUZUKI, Y.; SHINOHARA, Y.; SHIBUYA, M.; IKEDA, H. Recent development of hydroponics in Japan. In: INTERNATIONAL CONGRESS ON SOILLESS CULTURE, 6., 1984, Lunteren. Proceedings...Lunteren: International Society of Soiless Culture, 1984. p. 661-672.

TONIOLLI, C.B.; BARROS, I.B.I. Performance de cultivares de alface durante o verão no município de Porto Alegre. Horticultura Brasileira, Brasília, v. 14, n. 1, p. 125, 1996.
WOLF, B. Improvements in azomethine-H method for determination of boron. Communications in Soil Science and Plant Analysis, v. 5, n. 1, p. 39-44, 1974.

YOKOYAMA, S.; MÜLLER, J.J.V.; SILVA, A.C.F. "EMPASC-357-litoral": nova cultivar de alface para verão. Horticultura Brasileira, Brasília, v. 9, n. 1, p. 28, 1991.

ZATARIN, M. Comportamento de progênies de alface (Lactuca sativa L.) em diferentes épocas de plantio. Piracicaba: ESALQ, 1985.90 p. (Tese mestrado).

MELLO, S.C.; VITTI, G.C. Desenvolvimento do tomateiro e modificações nas propriedades químicas do solo em função da aplicação de resíduos orgânicos, sob cultivo protegido. Horticultura Brasileira, Brasília, v. 20, n. 2, p. 200 - 206, junho 2.002.

\title{
Desenvolvimento do tomateiro e modificações nas propriedades quími- cas do solo em função da aplicação de resíduos orgânicos, sob cultivo protegido $^{1}$
}

\author{
Simone C. Mello ${ }^{2}$; Godofredo C. Vitti ${ }^{3}$ \\ ${ }^{2}$ Rua das magnólias, 135, J. Novo Mundo, 13.211-610 Jundiaí-SP; ${ }^{3}$ ESALQ - Departamento de Solos e Nutrição de Plantas, C. Postal \\ 09, 13.418-900 Piracicaba-SP; E-mail: sicmello@zaz.com.br
}

\section{RESUMO}

O experimento foi conduzido de fevereiro a agosto de 1997 no município de Piracicaba (SP), a fim de avaliar os efeitos de doses e resíduos orgânicos no desenvolvimento do tomateiro (Lycopersicon esculentum Mill) cultivado em estufa e nos atributos químicos de um solo Podzólico vermelho-amarelo abrupto, A moderado, textura arenosa/média. $\mathrm{O}$ delineamento experimental foi de blocos casualizados em esquema fatorial $3 \times 4$, sendo usados três resíduos orgânicos [composto de lodo de cervejaria e cavaco de eucalipto (CLC), composto de lixo (CL) e cama de frango (CF)] e quatro doses equivalentes a 0 ; $100 ; 150$ e $200 \mathrm{~kg} \mathrm{ha}^{-1}$ de N, com quatro repetições. A produção de frutos de tomate não aumentou com a adição dos materiais orgânicos. A aplicação de $\mathrm{CF}$ reduziu o $\mathrm{pH}$ e o teor de $\mathrm{Mg}$ no solo. As doses do CLC elevaram o conteúdo de matéria orgânica, o teor de cálcio trocável e a capacidade de troca de cátions do solo. O CL, por sua vez, não alterou as propriedades químicas do solo.

Palavras-chave: Lycopersicon esculentum, adubação orgânica, cama de frango, composto de lixo, nitrogênio.

\begin{abstract}
Development of tomato and changes in soil properties with organic materials application in greenhouse

An experiment was carried out between February and August/ 97 to evaluate the effects of different organic wastes on the growth of tomato (Lycopersicon esculentum Mill) plants and on the chemical properties of an Ultisol soil. The experimental design was of complete randomized blocks with four replicates and treatments disposed in a factorial $3 \times 4$ : three organic wastes [malt residue and eucalyptus chip compost (CLC), urban solid waste compost (CL) and chicken litter (CF)] and four rates equivalent to $0 ; 100 ; 150$ and $200 \mathrm{~kg} \mathrm{ha}^{-1}$ of $\mathrm{N}$. The fruit yield did not increase with organic waste additions. CF application decreased the $\mathrm{pH}$ and exchange $\mathrm{Mg}$ of soil. CLC addition increased the organic matter; exchange $\mathrm{Ca}$ and cation exchange capacity of soil. However, CL did not change the soil chemical properties.
\end{abstract}

Keywords: Lycopersicon esculentum, organic manure, chicken litter, urban solid waste, nitrogen.

(Aceito para publicação em 15 de fevereiro de 2.002)

\begin{abstract}
$\mathrm{C}$ om o surgimento de novos processos de tratamento que permitem a redução do potencial poluidor dos resíduos orgânicos, o uso agronômico deles, como fonte de nutrientes às plantas e como condicionadores dos solos, tem se constituído em alternativa interessante na preservação da qualidade ambiental.
\end{abstract}

Além de possuírem matéria orgânica, que pode melhorar as propriedades físicas, químicas e biológicas do solo, os materiais orgânicos contêm nutrientes, dentre eles o N. Para espécies olerícolas, como o tomateiro, que apresenta alto requerimento por nutrientes em tempo relativamente curto, os materiais orgânicos são normalmente em- pregados visando suprir parte da necessidade de $\mathrm{N}$ pela planta, uma vez que a liberação desse nutriente depende da taxa de mineralização do material orgânico. Gerber et al. (1981) obtiveram aumento de $25,5 \%$ na produção de tomate com a aplicação de lodo de esgoto em quantidade equivalente a $112 \mathrm{~kg} \mathrm{ha}^{-1}$ de $\mathrm{N}$, em relação à adição de 112-67-67

\footnotetext{
${ }^{1}$ Parte da Tese de Doutorado apresentada ao Departamento de Solos e nutrição de plantas da ESALQ/USP, pelo primeiro autor.
} 